\title{
Adaptation and Nostalgia
}

\author{
COLLEEN KENNEDY-KARPAT*,®
}

\begin{abstract}
This essay highlights the shared critical terrain of adaptation and nostalgia: how they critically juxtapose the past with the present, and how they underscore the impossibility of return while also relying on prior experience. It also explores nostalgia's effect on personal responses to adaptations and its interaction with textual form. Drawing from various areas of literary, media, and performance studies, including film adaptations of children's literature, Watchmen and its screen adaptations, and Disney's live-action remakes, this essay underscores how both nostalgia and adaptation are inherently multivalent concepts, and how they each rely on perspective to generate critical meaning.
\end{abstract}

Keywords: Memory, history, race, remediation, fandom, form.

Our memories of the past, our experience of the present, and our anticipation of the future are forever intertwined. This temporal and emotional entanglement has been a primary tenet of nostalgia since the term was first coined, though its remit has since exceeded the individual to enter shared, cultural spaces as well. While nostalgia may be understood as a failure or at least a reluctance to adjust to changing circumstances, it can also prompt critical reflection on the past that productively shapes things yet to come. In this sense, nostalgia can be an adaptive impulse, even if the tendency for nostalgia to blur temporal boundaries contrasts with the relentlessly future-facing, linear chronology of adaptation. While the Association for Adaptation Studies adopted the theme of 'Returns' for its annual conference in 2017, at their core, both adaptation and nostalgia involve the impossibility of return: adaptation to its source(s), and nostalgia to inaccessible space(s) and time(s). Both emerge and exist in the present, yet they also remain fixated on prior experience.

Still, nostalgia does not define nor even dominate all encounters with the past, nor does it inspire or explain all adaptations. Amidst increased scholarly interest in nostalgia as a social phenomenon, Tobias Becker warns of an interdisciplinary discourse that sees it as 'a catch-all term potentially describing any form of engagement with the past' and critiques this overly loose approach in which 'instead of raising questions - who is nostalgic for what and why - the nostalgia discourse sets up the straw man of a universal and uniform zeitgeist' (235). Bringing nostalgia criticism into the realm of adaptation studies, the essays in this special issue use adaptation and intertextual strategies to pose the questions whose nostalgia? and why this nostalgia? Each chapter offers a particular

*Bilkent University Faculty of Art Design and Architecture, Communication and Design, FADACOMD, Bilkent Universitesi, Ankara,UniversitelerMah.E-mail:kenkar@bilkent.edu.tr 
critical lens on the intersection of adaptation and nostalgia: from personal response to collective spirit, and from national identity to narrative interconnection. These studies show how, by asking who and why, discourses of adaptation and nostalgia can inform one another without collapsing the conceptual boundaries that separate them. We can discuss 'nostalgic adaptation' without confusing the textual aspects of its adapted status with those that make it nostalgic, even though many such traits might belong to both categories.

While adaptation encompasses both process and product, nostalgia operates as a response, one that many have identified as a coping mechanism for people faced with momentous social change (e.g., Boym, Niemeyer). As the world is seeing now with COVID-19, people respond in many ways to the general conditions of a global pandemic, and their particular circumstances also shape their response. These social and personal foundations produce a variation of experience that dovetails with the need to acknowledge multiple nostalgias. As Stuart Tannock notes, 'nostalgic narratives may embody any number of different visions, values, and ideals. And, as a cultural resource or strategy, nostalgia may be put to use in a variety of ways' (454). Nostalgia shapessometimes profoundly - our relationships with people, places, objects, and texts, yet nostalgia itself is none of these things. Nostalgia is reactive; it emerges in response to stimuli that can come from the outside world or from one's own memories. It is also subjective; the same object that provokes one person's richly nostalgic experience might have no such effect on another. Moreover, a person who repeats an experience that once triggered a nostalgic response might discover that these feelings are as elusive as the past itself: Proust's next batch of madeleines might well have produced little more than a stomachache. And would we understand Proust's gluttony to be driven by nostalgia for his past, or by nostalgia for his prior reverie - and is this distinction even worth making?

The past that figures into both adaptation and nostalgia does not have to be distant; indeed, to borrow a line from William Faulkner, it doesn't even have to be past. Svetlana Boym's assertion that nostalgia can go 'sideways' as well as backwards can be productively mapped onto the intertextual connections of sequels, prequels, spinoffs, and textual pluralities of all kinds - that is, onto what Amanda Ann Klein and R. Barton Palmer have called media multiplicities (Boym xiv; Klein and Palmer 1). Some, like transmedia franchises, rely on the relatively close proximity of sequential releases across several platforms; others, like the remake, are not defined by temporal distance to their source. What is crucial in any time frame is a sense of displacement, of recognizing that past experience is distinct from the present. This infrangible distance, and the lingering attention granted it by the adaptive and/or nostalgic impulse, becomes a locus of personal and cultural interrogation.

In contrast to the affective nature of nostalgia, adaptation and other media multiplicities function textually, circumscribing nostalgia within certain recognizable forms. Although the limits of textuality may be debatable, any given text can stand as an empirically real object, in contrast with nostalgia's ineffable quality. If the adaptive process can predict or cultivate a nostalgic response, then one role that adaptation can play as a cultural product is to help its audience(s) come to terms with the inevitability of change. A fixation on fidelity - whether seen as an object of scorn or an essential part 
of the field - echoes Boym's notion of restorative nostalgia, which idealizes the past and attempts to reconstruct it in the present. The dangers of restorative nostalgia have been well noted in popular discourse, as in humourist John Hodgman's oft-repeated dismissal of nostalgia as a 'toxic impulse', as well as in scholarly examinations of, say, nostalgia's role in the rise of the global right (Goren). Indeed, Tannock blames much of the bristling response to nostalgia studies on the seeming omnipresence of nostalgia in conservative and reactionary political rhetoric (455). Adaptation studies can help elucidate the study of mediated nostalgia by echoing the question 'fidelity to what?' in the questions whose nostalgia? and nostalgia for what?

Yet restorative nostalgia, like fidelity discourse itself, does not have a stranglehold on adaptation. Free adaptations often incorporate what Boym calls reflective nostalgia, which unlike restorative nostalgia does not aim to recapture or reconstitute what has been; rather, reflective nostalgia distils the lessons that prior experiences can hold for the present, allowing for alterations or even distortions of historical truth in the service of its critical mission. Following Laurence Raw and Defne Ersin Tutan's assertion that all historical narrative can be understood de facto as adaptation invites further attention to how reflective nostalgia can repurpose the past to manage the present (10). In conceptualizing the 'imaginative, and performative, operation' of memory - an operation that also extends to adaptation - Pam Cook emphasizes audiences' awareness that 'the representation is not the same as the real thing', as well as their 'critical assessment of the authenticity of the reconstruction' (4). This notion of an 'authentic' representation of the past can be aligned with fidelity in adaptation, but because both fidelity and authenticity are constructs, it matters a great deal who takes charge of their construction.

\section{WHOSE NOSTALGIA?}

Understanding which texts generate adaptations and why is a complex task, with many different models addressing a range of factors from industry influence (Murray) to biological survival (Bortolotti and Hutcheon) to cultural value (Kennedy-Karpat and Sandberg). With regard to nostalgia, one key question is whose nostalgia deploys the most adaptations, reboots, and other multiplicities; one perhaps overly glib answer to this question would be the group who is willing to pay the most, collectively, to keep activating their nostalgic response. The implicit or explicit pressure that nostalgic fans place on adapted and franchise productions carries significant implications for media industries. But which fans hold the most sway, and what are the objects of their nostalgia?

Nostalgic response readily adheres to texts first experienced during one's youth. A fan claiming that any given adaptation, remake, or franchise extension 'ruins their childhood' (to cite the mildest version of this refrain) is essentially nostalgic in their complaint. But what is being betrayed, and at whose expense? In some cases, the betrayal is not at all textual. Examining the Hunger Games film adaptations, Ebony Elizabeth Thomas unpacks the backlash against multiracial actor Amandla Stenberg's casting as Rue despite the novels' repeated indications that the character ought to be understood as non-white. 'The discerning reader', Thomas argues, 'can detect the ways that [author Suzanne Collins] demonstrates that Rue is plausibly descended from the contemporary Black US population'- so that what some (mostly white) readers perceive 
as flagrant infidelity actually hews closely to Collins' novels (61). This racist backlash suggests that fidelity to whiteness, not (just) fidelity to the text, plays a major role in the politics of adaptation. Such an insistence on fidelity to whiteness - even when a character's whiteness is falsely presumed - can be couched in the rhetoric of nostalgia, underscoring whose nostalgia is valued in the adaptive process.

While this screen portrayal of a non-white Rue has textual fidelity on its side, racebent casting offers a different adaptive strategy. Racebending means that an existing character, usually but not always white, is portrayed by a performer of a different race, and it may be tempting to view such tactics as a substantive challenge to predominant cultural whiteness. ${ }^{1}$ While racebending may indeed alienate viewers whose attachment to white supremacy (nostalgic or otherwise) frames their reception of adapted texts, Kristen J. Warner criticizes this practice as 'plastic representation': an evasion or lack of racial and cultural specificity in media representations of minorities. If we assume that 'meaningful diversity occurs when [...] different-looking bodies appear on screen', and pay little attention to the characters being portrayed through these bodies, Warner argues, this then leads to

a set of dueling consequences: first, that any representation that includes a person of color is automatically a sign of success and progress; second, that such paltry gains generate an easy workaround for the executive suites whereby hiring racially diverse actors becomes an easy substitute for developing new complex characters. The results of such choices can feel-in an affective sense - artificial, or more to the point, like plastic.

Racebent casting has the potential to invoke multiple nostalgias - as Thomas observes with Hermione Granger's reception among non-white readers of the Harry Potter series (152-6) - but Warner's notion of plastic representation cautions against overly simplistic thinking around racebent adaptations. In terms of the quality of representation made possible by adaptation, it matters more that, for instance, Barry Jenkins has brought James Baldwin's novel If Beale Street Could Talk (2018) to the screen than it does to have Disney casting Black actors Halle Bailey as Ariel in a live-action Little Mermaid and Jelani Alladin as Broadway's Hercules (Kroll; Lefkowitz). The broader role of nostalgia in Disney's spate of self-adaptations is discussed below; here, the crucial point is that whether or not the attempt to expand the nostalgic resonance of existing characters through racebent casting might prove effective, even the best-known and -received examples fall short of transformative representation.

Remakes are another category where nostalgia figures prominently in reception, as they are often met with resistance, boycotts, or generally unfavourable reactions from devotees of the initial release(s) (Mee). The vitriolic reaction to Ghostbusters (2016) - a remake in which four women update the roles originated by men in Ivan Reitman's 1984 film Ghostbusters and its 1989 sequel - illustrates how audiences can reject new intertexts whose changes upend their nostalgic relationship to existing text(s). At the time of this writing, IMDb's top user review for Ghostbusters (2016) conveys an underwhelming assessment (4 out of 10 stars) that is firmly grounded in nostalgia: 'Because there are fans of this franchise going back 35 years, history matters. And this installment just destroyed all of that' (AlsExGal). As for what, exactly, was 'destroyed', the review gestures rather unconvincingly towards its predecessor's comedic structure: 'The humor in 
this film is very forced, broad, and silly, where the original Ghostbusters film featured dry intelligent humor often coming from just who the characters were and how they interacted' (AlsExGal). Meanwhile, professional critics took note of the sexist backlash against the cast and the racist social media trolling that made lead actor Leslie Jones a particular target (Woolf).

The failure of Ghostbusters (2016) to secure a positive nostalgic response nixed any prospect of a full reboot from this foundation. Yet the studio didn't give up on the franchise: instead, Columbia Pictures has produced a new sequel, Ghostbusters: Afterlife (which, at the time of this writing, is awaiting a post-COVID release). This sequel revisits many characters from the 1980s and puts Jason Reitman, son of the original Ghostbusters director Ivan Reitman, in the director's chair. The studio's response indicates the lengths the industry will go to mine (some) fans' nostalgia, underscoring both the fiscal stakes of adaptive nostalgia and the willingness to cater to misogynist bigots if executives believe that they will generate the surest profits. Where nostalgia attaches to texts, 'history matters' because nostalgia matters to many fans' decision to open their wallets.

As Thomas Leitch points out, 'exceptional fidelity' is not the norm in adaptation, but when it does happen it underscores an imbalance of cultural value between the source(s) and the new adaptation (Discontents 127-8). This imbalance may stem from formal biases, such as the belief that literary texts are inherently more worthy than screen texts, but it can also be rooted in the perceived clout of a fanbase that has pledged its allegiance to a canonical source. Whether the consensus about cultural value is presumed or proven, it means that producers see an adaptation's connection to its source as a selling point for target audiences, meaning that any 'infidelities' to this presold property are seen as a liability for future profits (Leitch, Discontents 127-8).

The concern over pleasing these presold fandoms is not baseless. Considering HBO's recent adaptation of Watchmen (2019), comics aca-fan ${ }^{2}$ William Proctor describes the graphic novel from writer Alan Moore and artist Dave Gibbons as 'a sacred, seminal text, one that perhaps should never be adapted nor extended with sequels, prequels, etc., or else the sanctity of the original would be defaced in some way - at least in the minds of purists (of which I am one, admittedly)'. Even after he concedes HBO's success with the Watchmen series, Proctor insists on the power of fans and of his own fandom:

Part of being a fan [is that] we fiercely protect our treasured objects from outside incursion, even as we are intimately aware that these are symbolic, psychic attacks. Yes, the comic book Watchmen still stands on my shelf, and yes, I can ignore the sequels, prequels etc. and embrace the comic as the 'one text to rule them all'. Yet I can't help but think that the comic has been symbolically assaulted in some way, and as a consequence, is no longer as unique as it once was.

This sentiment radiates restorative nostalgia, a yearning for an irretrievable time before Watchmen was ever adapted, back when it was still widely considered to be unfilmable. After all, adaptations and franchise extensions, once released, can hardly be taken back.

In all of its different iterations, Watchmen also demonstrates Katharina Niemeyer's assertion that media can create 'nostalgia for a past that has never been' (10). The book grapples with nostalgia most compellingly in its narration of an alternate 
history that produces a unique vision of the present - which here means the midto-late 1980s. Jacob Brogan sees in the graphic novel a 'playfully plural approach to history' that jumps 'backwards, forwards, and sideways in time' in order to comment on the political moment of its creation (214). This follows Boym's conception of nostalgia as a force that binds the past to both present and future, making nostalgia 'retrospective but also prospective', where the 'fantasies of the past determined by needs of the present have a direct impact on realities of the future', thus compelling us to 'take responsibility for our nostalgic tales' (xvi). While he suggests that the book respects this responsibility and uses nostalgia to create a potent social critique, Brogan argues that the 'perverse fidelity' of Zack Snyder's 2009 film adaptation undermines its capacity for relevant political commentary-even if, as Suzanne Scott suggests, Snyder's 'fannish sense of fidelity' probably landed him the job and continues to serve as his calling card in Hollywood (Brogan 215; Scott 440). Snyder's hyperfidelity to the graphic novel paradoxically refuses to engage with the particularities of Moore and Gibbons' nostalgic framework, resulting in a film that 'erases its own moment, as if it were struggling to project itself backwards in time' (Brogan 214-5).

Under showrunner Damon Lindelof, the most recent screen version of Watchmen presents its own intricate and consequential engagement with nostalgia. In terms of both production and story chronologies, the HBO series is more properly a sequel than an adaptation, as the action takes place thirty years after the events of the book. While several key characters originate in the graphic novel, many are either introduced for the first time or see their story drastically expanded. As if taking Brogan's critique as a challenge, the Watchmen series frames the present - this time, an alternate 2019for maximum resonance with actual history and its own narrative fantasy, lending a deeply critical purpose to the proceedings. Grégory Pierrot notes that in the series, 'history does not repeat itself: it rewinds, reruns, and is remade, new characters appearing under new titles and masks to re-enact the same old story', one defined by 'racial masquerade'. Importantly, this is not the 'same old story' of the graphic novel, as Moore and Gibbons barely address race. Rather, Pierrot refers here to the foundational racism of the United States.

The treatment of race and racism in Lindelof's Watchmen emerges most forcefully in a pivotal moment when protagonist Angela Abar (alias Sister Night) overdoses on a drug very pointedly called Nostalgia, a pharmaceutical concoction that allows the user to relive memories. There is significant risk if a person takes a dose made from someone else's memories, but this is what Angela does, jolting her psyche into her grandfather's past. But this is not a wistful glimpse of halcyon days: what Angela experiences is relentless and often violent racism, both systemic (his troubled rise through the police force) and individual (his harrowing escape from hanging at the hands of a lynch mob). This struggle finally pushes the young man, named Will Reeves, to adopt the persona of masked superhero Hooded Justice - a character that appears briefly in Moore and Gibbons' graphic novel, but without any hint of back story. Familiarity with the source lends nostalgic overtones to the presence of Hooded Justice, while the invention and extensive development of his alter ego Will Reeves is a retcon that pushes all of Watchmen into uncharted territory. 
The HBO series declares to tremendous effect in its first episode exactly whose nostalgia shapes its perspective on history by showing Reeves' memories of the 1921 massacre in Tulsa, Oklahoma, a historically real outburst of white supremacist violence which brought scores of deaths and massive destruction to a predominantly Black area of the city. This horrific episode had been relegated to a historical footnote, if it was mentioned at all, until Watchmen revived it in the national memory: two days after the premiere of the ninth and final episode, the Washington Post reported new evidence of mass graves in Tulsa that may contain victims' remains (Brown). As author N. K. Jemisin tweeted, 'Decades of historians have been trying to let the world know about this massacre, and it took an alternate history comic book drama to break the wall of racism. [I don't know] whether to laugh or cry, but let no one say fiction has no power in the real world' (@nkjemisin). By shifting the central nostalgic perspective in the Watchmen universe, Lindelof's show has shed powerful light on America's lived history.

\section{NOSTALGIC FORMS}

Besides nostalgia's capacity to invent or reshape the past, mediated nostalgia also revolves around form. As Niemeyer observes, 'media are very often nostalgic for themselves, their own past, their structures and contents' (7). Adaptation taps into this engagement with form along lines that are already well drawn (e.g., Hutcheon, Leitch Discontents). But a transcoding-dependent view of adaptation cannot claim a monopoly on mediated nostalgia. Even without adaptation or other intertextual intervention, returning to the same text repeatedly over time forces confrontation with change and can produce a nostalgic response. Indeed, this response occurs in significant measure precisely because we cannot help but perceive the changes happening within ourselvesthough whether we recognize this at a conscious level is another matter.

Changes are also borne by and within the text itself. In The Virtual Life of Film, D. N. Rodowick frames cinema in particular as an 'art of repetition' rather than reproduction, noting that 'each repetition is also a difference', particularly where the materiality of celluloid makes film uniquely susceptible to the effects of repeated screening and handling (20). Yet the same is true in other media, where cross-platform transitions and transfers mark different, but equally significant changes in the text: the complete DVD set of, say, The Sopranos (1999-2007) is not television; films that win over festival juries in European theatres proceed to streaming services around the world; books make the leap from paper to e-book editions. Each resurgence in a different form marks another repetition and opens the text to changes that depend on medium-specific capabilities and conventions. Such relationships suggest a nostalgic function for remediation as an intertextual strategy. Jay David Bolter and Richard Grusin define remediation as creating 'refashioned and improved versions' of older media for circulation through new media forms, and vice versa (15). What I propose to call remediative nostalgia comes from integrating established, medium-specific codes with new platforms and new texts despite technological and cultural developments that could free these new forms from these outmoded codes.

The point of remediative nostalgia lies precisely in the revival of outmoded platforms as a way to tap into past rituals and affects that connect to mediated experience. It not only emphasizes the continuation of these past forms into the present, but also 
insists that past and present can coexist by using one another to create meaning. Drew Morton sees remediative nostalgia in Edgar Wright's Scott Pilgrim vs. the World (2010), which brings 8-bit aesthetics to a film adaptation of Bryan Lee O'Malley's eponymous graphic novel; elsewhere, I have argued that Marjane Satrapi's film adaptation of her own graphic novel Chicken with Plums (book 2007; film 2011) uses remediative nostalgia to maximize its transnational resonance. Still other intertextual conventions, including director's cuts and altered re-releases, underscore how specific transformations of a text can shift the tenor or degree of its nostalgic impact. Considering the long and storied history of the Star Wars transmedia universe, even before Disney took control and expanded it with new films (which have launched their own nostalgic critiques), creator George Lucas met with hostility from fans bemoaning both the prequels and his updates to the initial trilogy. Inspired by these fannish recriminations, Eddie King and Tyler Marshall parodied Gotye's pop song 'Somebody That I Used to Know' with a petulant Lucas declaring that fans will 'never get a Blu-Ray of the Star Wars that you used to know'.

Such rereleases, whose repeated revisions disavow the possibility of permanent replacement, might align less with nostalgia than with hauntology. Related to nostalgia, though also distinct from it, Mark Fisher defines hauntology as 'the virtual agency of the no longer'; the hauntological text renders a state of time out of joint, a phrase Jacques Derrida borrows from Hamlet to describe the phenomenon $(21,18)$. Hauntology lays bare how media's outdated ways of seeing combine with a narrow scope that sees only the past, producing habits that, according to Fisher, limit the possibility of future invention: 'relentless technological upgrades - the same thing, seen and/or heard on a new platform - disguise the disappearance of formal innovation' (18).

Disney's 'live-action' remakes offer another illustrative corpus where hauntology collides with adaptation and nostalgia. Indeed, much of the criticism surrounding these remakes - a long and rapidly growing list that includes Beauty and the Beast (1991/2017), Aladdin (1992/2019), The Lion King (1994/2019), and Dumbo (1941/2019) — claims that they don't have much to offer beyond nostalgia (e.g., Nilles). Yet these Disney-to-Disney adaptations all showcase state-of-the-art digital cinematography and postproduction effects, creating what Ian Olney calls an 'adaptation spectacular' that values technical achievement over textual fidelity (167). But where Olney sees these as competing priorities, Disney's remakes aim to combine them, resulting in films whose technical virtuosity is motivated precisely by their insistence on fidelity. Crucially, the story remains very much the same. The interest in these 'live-action' remakes - some of which, frame by frame, show proportionally more pixels than people-lies in their use of digital technologies to recreate the studio's most fanciful hand-drawn animation using bigticket stars and computer-generated effects instead of ink and paint. Disney's Broadway adaptations offer similarly hauntological pleasures, deploying top-notch stagecraft for new performers to sing - literally - the same old tunes. While recycling stories across platforms might hold nostalgic appeal, it also distracts from the fact that what might look 'new'-like casting Black actors as Ariel and Hercules - does not in fact offer meaningful formal or social advancement (Warner).

This multiplication of forms and platforms highlights both the hauntological branding of the Walt Disney Company and the contingency of nostalgia among 
different audiences. The generation gap between an animated film and its 'live-action' remake or Broadway show means that parents and caregivers may be introducing their charges to their own cultural past via stories that they experienced for the first time at a similar age, but in a different form. The simultaneous availability of sources and intertexts means that young people can and will understand the new performances as adaptations, but they are less likely to have nostalgic attachment to 'originals'. Still, whether or not a text is received primarily as an adaptation, it can be amenable to that interpretive approach; similarly, nostalgia is best understood as a possible rather than a necessary response to textual engagement.

As a 'structure of feeling', in Tannock's words, nostalgia is particularly reliant on encoding and decoding for specific formal contexts (460). On the production side, particularly for visual media, aspects of the spectacle can be designed to evoke a nostalgic response: production design, costuming, dialogue, and performance. Indeed, Fredric Jameson's notion of 'nostalgia film' focuses primarily on the realm of design even as he laments its narrative emptiness. These same elements can also drive novel-to-film adaptations, particularly when these are understood as a genre unto themselves (Leitch 'Genre'). However, the effectiveness of this production setup is only as strong as its reception allows. To this end, Paul Grainge proposes a useful distinction between nostalgia as a 'consumable mode' from nostalgia as an 'experienced mood' (27). While an emphasis on consumption implicates producers as well as audiences, the 'experienced mood' underscores the fundamental importance of reception. Adaptation, too, can be understood both as a logic of consumption that (de)prioritizes future textual encounters based on prior experience, and as a means of shaping interpretations of and affective responses to intertexts. Both adaptation and nostalgia add layers to the narrative experience, aiming to appeal to the knowledgeable consumer through their prior awareness while also hoping to satisfy first-time audiences (Scolari 592).

The question is whether, beneath these layers of meaning, there is anything uniquely valuable in a text that revives something that has come before. Aiming to diverge from what he sees as the near-reflexive rejection of nostalgia in cultural scholarship, Tannock asks a key question: 'Does the nostalgic text provide a relief from, or a resource for confronting the sources of the anxieties, fears, and frustrations to which nostalgia is a response?' (457-8) We might repeat this question, replacing nostalgic/nostalgia with adapted/adaptation, and then consider these implications together. The essays collected in this issue each address this intertwined question in different ways, and they all reflect two key attributes of both nostalgia and adaptation: their intrinsic multiplicity and their reliance on individual perspective.

\section{In this special issue}

In 'Thomas Pynchon and Paul Thomas Anderson's Inherent Vice(s) and the Affective Politics of Nostalgia', Eric Sandberg frames a case study of Pynchon's only screen adaptation to date that also examines the promotional trailers that were released to support both the book and the film. In both its novel and film incarnations, Inherent Vice engages with nostalgia as a collective feeling around or about shared socio-political realities as well as a deeply personal emotional response to individual circumstances. Yi Li also approaches nostalgia as a combination of political and personal expression 
in 'Melancholic Nostalgia, Identity Crisis and Adaptation in 1950s Hong Kong', a comparative study of film adaptations of Ba Jin's novel Family that were made in Hong Kong and mainland China. Examining these adaptations within the political and film industry contexts of mid-twentieth century Hong Kong, Li argues that exiled filmmakers' selection and interpretation of popular mainland source texts on the big screen frames nostalgia as a key factor in the emerging wenyi genre that went on to shape the whole of Hong Kong cinema during the Cold War.

In 'Nostalgia and Retcons: The Many Returns, Homecomings, and Revisions of the Halloween Franchise (1978-2018)', Adam Ochonicky maps nostalgia onto the practice of retroactive continuity, or retcon, that is a common denominator of many screencentred multiplicities. He argues that retconning presumes a nostalgic view of prior texts, showing how retconned entries in a long-running franchise like Halloween rely on nostalgia in their narratives, in their form and themes, and even in their marketing campaigns. Looking at a different set of multiplicities, Brunella Tedesco-Barlocco finds several threads of nostalgia woven into the popular television series Better Call Saul (2015-) in 'It's (Not) All Good, Man: Better Call Saul and the Nostalgic Reconstruction of an Ever-longing Character'. As a spinoff, the show has a nostalgic relationship to Breaking Bad (2008-13), which preceded it in terms of production chronology; however, in terms of character structure and narrative chronology, the spinoff moves in different temporal directions to connect with the original story world in various ways, each carrying specific implications for the show's expression of nostalgia.

Finally, using a theoretical lens to elucidate nostalgic expression, Irina Melnikova examines the hypertextual structures that interlink the films in Italian director Luca Guadagnino's 'Desire Trilogy'. Drawing on the theories of Gérard Genette, Lars Elleström, and Charles Sanders Peirce, Melnikova considers I Am Love (2009), A Bigger Splash (2015), and Call Me By Your Name (2017) alongside their various intertexts to understand how nostalgia reinforces transtextual connections not only across Guadagnino's films, but also across different modes of mediated expression.

\section{NOTES}

${ }^{1}$ Related to racebending is the practice of whitewashing, where a white actor plays a character known or reasonably presumed to be non-white, which also prioritizes fidelity to whiteness over textual fidelity. Examples of whitewashing abound, but Tilda Swinton's turn as a Tibetan mystic in Marvel's screen adaptation of Doctor Strange (2016) produced a noteworthy news cycle around the time of the film's release.

${ }^{2}$ Coined by Henry Jenkins and popularized through his blog, Confessions of an Aca-Fan, this term is a portmanteau of 'academic' and 'fan', referring to scholars who study media texts of which they are also professed and engaged fans.

\section{REFERENCES}

Aladdin. Directed by Ron Clements and John Musker. USA: Walt Disney Animation Studios, 1992. Aladdin. Directed by Guy Ritchie. USA: Walt Disney Pictures, 2019.

AlsExGal. Comment on Ghostbusters (2016). Internet Movie Database, 14 Dec. 2019. imdb.com/title/ tt1289401/. Accessed 13 Mar. 2020.

Beauty and the Beast. Directed by Gary Trousdale and Kirk Wise. USA: Walt Disney Animation Studios, 1991. 
Beauty and the Beast. Directed by Bill Condon. USA: Walt Disney Pictures, 2017.

Becker, Tobias. "The Meanings of Nostalgia: Genealogy and Critique." History and Theory 57.2 (2018): 234-50.

Bolter, Jay David and Richard Grusin. Remediation: Understanding New Media. Cambridge, MA: MIT Press, 2000.

Bortolotti, Gary R. and Linda Hutcheon. "On the Origin of Adaptations: Rethinking Fidelity Discourse and 'Success': Biologically.” Biocultures, Special Issue of New Literary History 38.3 (2007): 443-58.

Boym, Svetlana. The Future of Nostalgia. New York: Basic Books, 2001.

Brogan, Jacob. "Stop/Watch: Repressing History, Adapting Watchmen." The Politics of Adaptation. Eds. Dan Hassler-Forest and Pascal Nicklas. Basingstoke: Palgrave Macmillan, 2015, pp. 214-26.

Brown, DeNeen L. "In Tulsa, an Investigation Finds Possible Evidence of Mass Graves from 1921 Race Massacre." Washington Post, 17 Dec. 2019. washingtonpost.com/history/2019/12/16/tulsa-movescloser-learning-if-there-are-mass-graves-race-massacre/. Accessed 17 Dec. 2019.

Chase, David, creator. The Sopranos. HBO, 1999-2007.

Cook, Pam. Screening the Past: Memory and Nostalgia in Cinema. New York: Routledge, 2005.

Dumbo. Directed by Sam Armstrong, et. al. USA: Walt Disney Animation Studios, 1941.

Dumbo. Directed by Tim Burton. USA: Walt Disney Pictures, 2019.

Fisher, Mark. "What is Hauntology?" Film Quarterly 66.1 (2012): 16-24.

Ghostbusters. Directed by Ivan Reitman. USA: Columbia-Delphi Productions, 1984.

Ghostbusters. Directed by Paul Feig, performances by Kristen Wiig, Melissa McCarthy, Kate McKinnon and Leslie Jones. USA: Columbia Pictures, 2016.

Ghostbusters II. Directed by Ivan Reitman. USA: Columbia Pictures, 1989.

Ghostbusters: Afterlife. Directed by Jason Reitman. USA: Columbia Pictures, 2021.

Goren, Lilly J. "Fading Images: Politics and Nostalgia in the Age of Anxiety." Nostalgia in Contemporary Culture Interdisciplinary Conference, 4-5 June 2018, University of Southern Denmark, Odense, Denmark.

Grainge, Paul. "Nostalgia and Style in Retro America: Moods, Modes, and Media Recycling." fournal of American \& Comparative Cultures 23.1 (2000): 27-34.

Hodgman, John. "Nostalgia Is a Toxic Impulse." Tumblr, 4 Nov. 2018. johnhodgman.com/ post/179764090143/nostalgia-is-a-toxic-impulse. Accessed 11 Mar. 2020.

Hutcheon, Linda. A Theory of Adaptation. New York: Routledge, 2006.

If Beale Street Could Talk. Directed by Barry Jenkins. USA: Annapurna Pictures, 2018.

Jameson, Fredric. Postmodernism, or the Cultural Logic of Late Capitalism. Durham, NC: Duke UP, 1992.

Jenkins, Henry. Confessions of an Aca-Fan. henryjenkins.org. Accessed 8 Apr. 2020.

Kennedy-Karpat, Colleen. "Self-adaptation and Transnationality in Marjane Satrapi's Poulet aux prunes (2011)." Adaptation 8.1 (2015): 68-88.

Kennedy-Karpat, Colleen and Eric Sandberg, eds. Adaptation, Awards Culture, and the Value of Prestige. Cham: Palgrave Macmillan, 2017.

King, Eddie and Tyler Marshall. "'The Star Wars That I Used to Know' - Gotye 'Somebody That I Used to Know' Parody." YouTube, uploaded by Teddiefilms, 27 June 2012, youtube.com/ watch?v=qJlbPXZEpRE. Accessed 10 Mar. 2020.

Klein, Amanda Ann and R. Barton Palmer, eds. Cycles, Spinoffs, Remakes \& Reboots: Multiplicities in Film and Television. Austin: U Texas P, 2016.

Kroll, Justin. "Disney's Live Action 'Little Mermaid' Casts Halle Bailey as Ariel.” Variety, 3 July 2019, variety.com/2019/film/news/little-mermaid-halle-bailey-chloe-x-halle-1203234294/. Accessed 7 Apr. 2020.

Lefkowitz, Andy. "Hercules Footage Is Here! Watch Jelani Alladin, Krysta Rodriguez \& More 'Go the Distance' in Central Park." Broadway, 6 Sept. 2019, broadway.com/buzz/196821/hercules-footageis-here-watch-jelani-alladin-krysta-rodriguez-more-go-the-distance-in-central-park/. Accessed 7 Apr. 2020.

Leitch, Thomas. "Adaptation, the Genre." Adaptation 1.2 (2008): 106-20.

---. Film Adaptation and Its Discontents. Baltimore, MD: Johns Hopkins U P, 2007.

Lindelof, Damon, creator. Watchmen. HBO, 2019.

The Lion King. Directed by Roger Allers and Rob Minkoff. USA: Walt Disney Animation Studios, 1994. 
The Lion King. Directed by Jon Favreau. USA: Walt Disney Pictures, 2019.

Mee, Laura. "The Hollywood Remake Massacre: Adaptation, Reception, and Value." Adaptation, Awards Culture, and the Value of Prestige. Eds. Colleen Kennedy-Karpat and Eric Sandberg, Cham: Palgrave Macmillan, 2017, pp. 193-209.

Moore, Alan and Dave Gibbons. Watchmen. 1986-1987. DC Comics, 2014.

Morton, Drew. "From the Panel to the Frame: Style and Scott Pilgrim." Vimeo, 10 Feb. 2013. vimeo. com/59355775. Accessed 10 Mar. 2020.

Murray, Simone. The Adaptation Industry: The Cultural Economy of Contemporary Literary Adaptation. London: Routledge, 2012.

Niemeyer, Katharina. Media and Nostalgia: Yearning for the Past, Present, and Future. Basingstoke: Palgrave Macmillan, 2014.

Nilles, Billy. "How Disney Is Turning Your Nostalgia into Billions One Live-Action Remake at a Time." E! Online, 19 Oct. 2019, eonline.com/news/1027655/how-disney-is-turning-your-nostalgia-into-billionsone-live-action-remake-at-a-time. Accessed 7 Apr. 2020.

@ nkjemisin. 'Because of 'Watchmen'. Decades of historians have been trying to let the world know about this massacre, and it took an alternate history comic book drama to break the wall of racism. IDK whether to laugh or cry, but let no one say fiction has no power in the real world." Twitter, 21 Feb. 2020. twitter.com/nkjemisin/status/1230605855940370441. Accessed 7 Apr. 2020.

Olney, Ian. "Texts, Technologies, and Intertextualities: Film Adaptation in a Postmodern World." LFA 2009, Special Issue of Literature/Film Quarterly 38.3 (2010): 166-70.

O’Malley, Bryan Lee. Scott Pilgrim vs. the World. Portland, OR: Oni Press, 2004.

Pierrot, Grégory. "We Wear the Masks." Africa Is a Country, 28 Feb. 2020. africasacountry.com/2020/02/ we-wear-the-masks. Accessed 5 Mar. 2020.

Poulet aux prunes. Directed by Marjane Satrapi and Vincent Paronnaud. France: Celluloid Dreams, 2011.

Proctor, William. "Who's Watching HBO's Watchmen?" CST Online, 24 Dec. 2019. cstonline.net/whoswatching-hbos-watchmen-by-will-brooker-and-william-proctor/. Accessed 2 Jan. 2020.

Raw, Laurence and Defne Ersin Tutan, eds. The Adaptation of History. Jefferson, NC: McFarland, 2013.

Rodowick, D. N. The Virtual Life of Film. Cambridge, MA: Harvard U P, 2007.

Satrapi, Marjane. Poulet aux prunes. Paris: L’Association, 2007.

Scolari, Carlos Alberto. "Transmedia Storytelling: Implicit Consumers, Narrative Worlds, and Branding in Contemporary Media Production." International fournal of Communication 3 (2009): 586-606.

Scott Pilgrim vs. the World. Directed by Edgar Wright. USA: Universal Pictures, 2010.

Scott, Suzanne. "Dawn of the Undead Auteur: Fanboy Auteurism and Zack Snyder's 'Vision."' A Companion to Media Authorship. Eds. Jonathan Gray and Derek Johnson, West Sussex: Wiley, 2013, pp. 440-62.

Tannock, Stuart. "Nostalgia Critique.” Cultural Studies 9.3 (1995): 453-64.

Thomas, Ebony Elizabeth. The Dark Fantastic: Race and the Imagination from Harry Potter to the Hunger Games. New York: New York UP, 2019.

Warner, Kristen J. "In the Time of Plastic Representation." Film Quarterly 71.2 (2017) filmquarterly. org/2017/12/04/in-the-time-of-plastic-representation/. Accessed 12 May 2019.

Watchmen. Directed by Zack Snyder. USA: Warner Brothers, 2009.

Woolf, Nicky. "Leslie Jones Bombarded with Racist Tweets After Ghostbusters Opens." The Guardian, 19 July 2016. theguardian.com/culture/2016/jul/18/leslie-jones-racist-tweets-ghostbusters. Accessed 11 Mar. 2020.

\section{ACKNOWLEDGEMENTS}

I extend my heartfelt gratitude to Niklas Salmose, Rune Graulund, and Eric Sandberg for spearheading the Nostalgia in Contemporary European Culture workshop in Växjö, Sweden in 2017 and a subsequent conference in Odense, Denmark the following year. My participation in both these events provided the impetus to pitch this special issue, and I extend my thanks as well to the editorial board of Adaptation for their support in putting it all together. 